\title{
An assessment of public health surveillance of Zika virus infection and potentially associated outcomes in Latin America
}

\author{
Leonelo E. Bautista ${ }^{1 *}$ and Víctor M. Herrera ${ }^{2}$
}

\begin{abstract}
Background: We evaluated whether outbreaks of Zika virus (ZIKV) infection, newborn microcephaly, and GuillainBarré syndrome (GBS) in Latin America may be detected through current surveillance systems, and how cases detected through surveillance may increase health care burden.

Methods: We estimated the sensitivity and specificity of surveillance case definitions using published data. We assumed a $10 \%$ ZIKV infection risk during a non-outbreak period and hypothetical increases in risk during an outbreak period. We used sensitivity and specificity estimates to correct for non-differential misclassification, and calculated a misclassification-corrected relative risk comparing both periods. To identify the smallest hypothetical increase in risk resulting in a detectable outbreak we compared the misclassification-corrected relative risk to the relative risk corresponding to the upper limit of the endemic channel (mean + 2 SD). We also estimated the proportion of false positive cases detected during the outbreak. We followed the same approach for microcephaly and GBS, but assumed the risk of ZIKV infection doubled during the outbreak, and ZIKV infection increased the risk of both diseases.
\end{abstract}

Results: ZIKV infection outbreaks were not detectable through non-serological surveillance. Outbreaks were detectable through serologic surveillance if infection risk increased by at least 10\%, but more than $50 \%$ of all cases were false positive. Outbreaks of severe microcephaly were detected if ZIKV infection increased prevalence of this condition by at least 24.0 times. When ZIKV infection did not increase the prevalence of severe microcephaly, 34.7 to $82.5 \%$ of all cases were false positive, depending on diagnostic accuracy. GBS outbreaks were detected if ZIKV infection increased the GBS risk by at least seven times. For optimal GBS diagnosis accuracy, the proportion of false positive cases ranged from 29 to $54 \%$ and from 45 to $56 \%$ depending on the incidence of GBS mimics.

Conclusions: Current surveillance systems have a low probability of detecting outbreaks of ZIKV infection, severe microcephaly, and GBS, and could result in significant increases in health care burden, due to the detection of large numbers of false positive cases. In view of these limitations, Latin American countries should consider alternative options for surveillance.

\section{Background}

Disease surveillance is an essential tool for the development of effective public health and patient care policies. During the last two years, Latin American countries have implemented surveillance of Zika virus (ZIKV) infection, newborn microcephaly, and Guillain-Barré syndrome (GBS) in response to ongoing outbreaks and concerns

\footnotetext{
* Correspondence: lebautista@wisc.edu

'Department of Population Health Sciences, School of Medicine and Public Health, University of Wisconsin at Madison, 610 Walnut Street, WARF 703, Madison, WI 53726-2397, USA

Full list of author information is available at the end of the article
}

about possible causal associations between these diseases. In most countries, these systems follow guidelines from international health agencies $[1,2]$, and are commonly based on the passive detection and report of cases by health care personnel to surveillance units in Ministries of Health. Surveillance reports suggest substantial increases in microcephaly prevalence and GBS incidence following ZIKV outbreaks [3, 4], but increases could be explained by intensified surveillance [5].

ZIKV-microcephaly-GBS surveillance systems have been in place for a short time and there are no data on their performance. We present an assessment of the 
expected performance of these systems, based on current knowledge and assumptions about disease frequency, accuracy of diagnostic tests, and hypothetical effects of ZIKV infection on microcephaly and GBS risk. Specifically, we evaluated under what conditions would outbreaks of these diseases be identifiable, and what would be the impact of false positive cases detected through surveillance on health care burden. Findings from this study could inform the implementation of surveillance systems in Latin America.

\section{Methods}

\section{Overall approach}

We evaluated the expected performance of a hypothetical surveillance system in a population of 10 million with a birth rate of 17.3/1000 population. These figures are close to the median population size and fertility rate in Latin American countries. We conducted separate evaluations for ZIKV infection, newborn microcephaly, and GBS surveillance.

We assumed the risk of ZIKV infection during a baseline, non-outbreak period $\left(\mathrm{RZ}_{0}\right)$, was $10 \%$, and individuals who got infected were no longer susceptible in a subsequent outbreak period [6]. We calculated the ZIKV infection risk during an outbreak $\left(R Z_{1}\right)$ as $\mathrm{RZ}_{0} \times \mathrm{RRZ}_{0 \rightarrow 1}$, where $R R Z_{0 \rightarrow 1}$ is a hypothetical relative increase in risk, and generated "true" $2 \times 2$ tables of period by ZIKV infection (Fig. 1 and Additional file 1, item 1). Then, we obtained $2 \times 2$ tables corrected for misclassification of ZIKV infection status and calculated the expected observed risk ratio (EORR) and the expected observed case ratio (EOCR) comparing the outbreak and non-outbreak period. By progressively increasing it from one to nine, we identified the minimum $R R Z_{0 \rightarrow 1}$ resulting in a detectable outbreak. We also calculated the proportion of false positive cases (PFP) identified through surveillance, an indicator of the added health care burden resulting from errors in ZIKV infection diagnosis.

We used the same approach to assess a possible GBS/ microcephaly outbreak during a ZIKV infection outbreak with $\mathrm{RZ}_{1}=2 \times \mathrm{RZ}_{0}$. However, we accounted for the number of new cases of ZIKV infection in our calculation of the risk of GBS/microcephaly during the outbreak. For instance, for GBS the risk during the outbreak period $\left(\mathrm{RG}_{1}\right)$ was calculated as $\left[\left(\mathrm{RG}_{0} \times \mathrm{NZ}_{(-)}\right)\right.$ $\left.\left.+\left(\mathrm{RG}_{0} \times \mathrm{NZ}_{(+)} \times \mathrm{HRI}_{\mathrm{Z} \rightarrow \mathrm{G}}\right)\right] /\left(\mathrm{NZ}_{(-)}+\mathrm{NZ}_{(+)}\right)\right]$, where $R_{0}$ is the baseline risk of GBS, $\mathrm{HRI}_{\mathrm{Z} \rightarrow \mathrm{G}}$ is the relative increase in GBS risk among ZIKV infected individuals, and $\mathrm{NZ}_{(+)}$and $\mathrm{NZ}_{(-)}$are the numbers of ZIKV infected and non-infected individuals during the outbreak, respectively. We obtained misclassification corrected $2 \times 2$ tables and calculated the EORR, EOCR, and PFP for each condition. To find a minimum resulting in a detectable outbreak, we probed for values of $\mathrm{HRI}_{\mathrm{Z} \rightarrow \mathrm{G}}$ of 1 , 5, and 10 for GBS and for values of $\mathrm{HRI}_{\mathrm{Z} \rightarrow \mathrm{M}}$ of $1,5,10$ and 15 for microcephaly.

Outcome misclassification-corrected $2 \times 2$ tables were obtained using standard formulae for the case of non-differential errors [7]. Specifically, if $\mathrm{A}=$ number of exposed cases, $\mathrm{B}=$ number of non-exposed cases, $\mathrm{C}=$ number of exposed non-cases, and $\mathrm{D}=$ number of non-exposed non-cases from the "true" $2 \times 2$ table, then the expected observed number of exposed cases would be [(A $\times$ test sensitivity $)+(C \times(1$ - test specificity $))]$. Also, the expected observed number of non-exposed non-cases would be $[(\mathrm{D} \times$ test specificity $)+(\mathrm{B} \times(1$ - test sensitivity $))]$. We assumed no changes in case definition or surveillance procedures occurred during the outbreak.

Surveillance guidelines do not specify when to declare an outbreak $[1,8,9]$. We applied the standard criterion of an incidence beyond two standard deviations above the baseline average, the upper limit of the endemic channel, as the cut point to identify an outbreak [10]. In consequence, we declared an

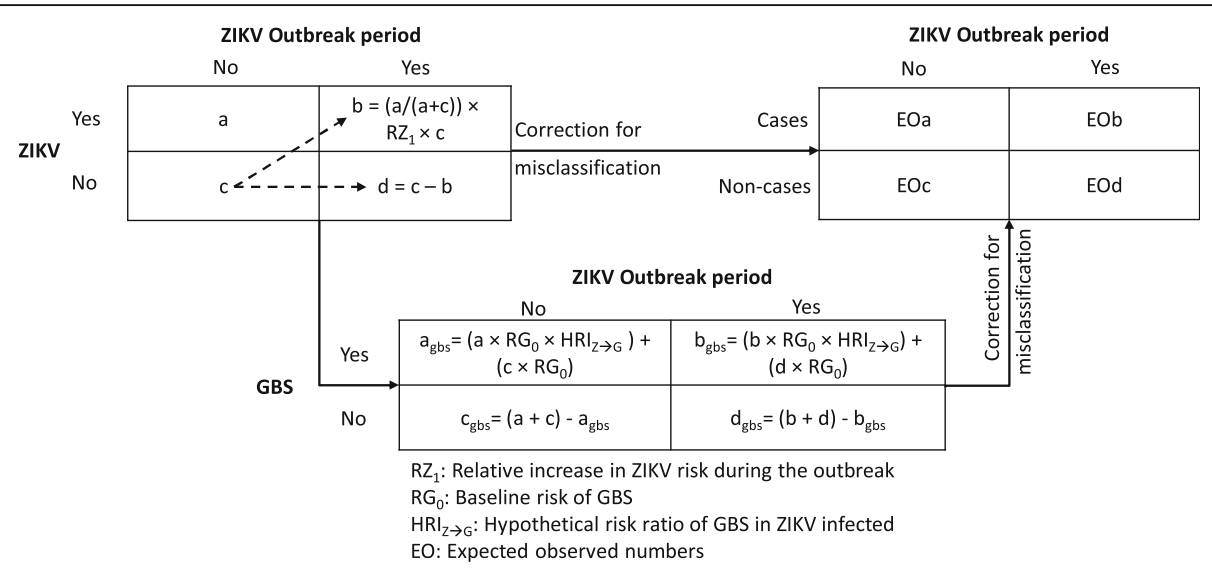

Fig. 1 Approach for comparing risk of Zika virus infection and related outcomes during outbreak and non-outbreak period 
outbreak happened if the $p$-value from a chi square test for the EORR was below 0.0227 .

\section{Zika virus infection}

The surveillance case definition used in Latin America: "Patient with rash with at least two or more of the following signs or symptoms: fever, usually $<38.5{ }^{\circ} \mathrm{C}$, conjunctivitis, arthralgia, myalgia, and peri-articular edema" [1], resembles the definition used by Duffy et al. in a study of an outbreak on Yap Island, Micronesia [11]. Duffy et al. reviewed medical records in all health centers to identify suspected cases and used ELISA tests for IgM antibodies and RT-PCR for ZIKV and dengue virus to confirm the diagnosis. They also conducted a serological survey in a random sample of the population. We used their data and formulae for screening studies with extreme verification bias $[12,13]$ to estimate the sensitivity and the specificity of the surveillance case definition in three scenarios (Additional file 1, item 2).

In the regular surveillance scenario only cases requesting medical care were detected, similar to Duffy et al.'s study [11], and sensitivity and specificity were 2 and $96 \%$, respectively. The enhanced surveillance scenario was similar to regular surveillance, but we assumed the case detection probability was five times higher in Latin America than in Yap Island [11]. In this case, sensitivity was $9.8 \%$ and specificity was $79.7 \%$. In the serological surveillance scenario all suspected cases of ZIKV infection were detected through a survey and infection was confirmed using the same tests used in the Yap Island study [11]. In this case, sensitivity was $37.7 \%$ and specificity was $81.1 \%$.

\section{Microcephaly}

We conducted separate assessments for all and severe microcephaly, traditionally defined as a head circumference $(\mathrm{HC})<2$ and $<3$ standard deviations (SD) below the mean, respectively $[14,15]$. Under these definitions the prevalences of all and severe microcephaly are 22.75 and 1.35/1000 newborn, respectively. We assumed ZIKV infection increased the risk of microcephaly in the baseline and outbreak period but only in newborn of women infected in that period.

We simulated $\mathrm{HC}$ values to estimate accuracy of a diagnosis of microcephaly (Additional file 1, item 3). First, we generated "true" $\mathrm{HC}$ values by randomly drawing one million observations from the $\mathrm{HC}$ distribution in Brazilian newborn (mean $34.2 \mathrm{~cm}, \mathrm{SD}$ 1.2) [16]. We obtained random errors from a normal distribution with mean 0 and SD equal to the intra-observer technical error of $\mathrm{HC}$ measurements (TEM) [17] in the WHO Multicentre Growth Reference Study [18], and added them to the true values [19]. We cross-classified individuals by applying the definition of all and severe microcephaly to the true (gold standard) and the error augmented values, and calculated the sensitivity and specificity of $\mathrm{HC}$ measurements. We also used estimates of sensitivity and specificity for all microcephaly, among low birth weight newborn $(\leq 2000 \mathrm{~g})$ from Bhushan et al. [20], and their TEM values to estimate sensitivity and specificity for severe microcephaly (see Table 2 for values of sensitivity and specificity).

\section{Guillain-Barré syndrome}

We used a GBS incidence of $2 / 100,000$ in our calculations. This value was taken from a published review in which incidence ranged from 0.4 to 4 cases $/ 100,000$ population in all but two out of 34 studies [21].

GBS diagnostic certainty could be very low, particularly in the early stages of the disease, and there is no clinical characteristic or biomarker that perfectly discriminates GBS from mimicking neurologic disorders [22]. The Brighton criteria is the standard tool to classify GBS cases by diagnostic certainty [23-25]. A certainty level $\leq 3$, recommended for surveillance case definition, was used in this analysis [1]. We estimated an average sensitivity of $82.1 \%$ from three published studies [23, 24, 26] (Additional file 1, item 4) and used specificities of 91.7, 88.9 , and $80.6 \%$, from the sole study on this issue, as far as we know [27]. However, we applied this specificity only to individuals with incident peripheral neuropathy, the key clinical feature that most commonly leads to a suspicion of GBS $[22,28,29]$, since only they could be falsely diagnosed as GBS cases. We used a random effects model to estimate the average incidence of peripheral neuropathy in published studies [30-40] and used the low and upper limits of its $95 \%$ confidence interval in the analysis (3.3 and 5.6/10,000; Additional file 1, item 5).

\section{Results}

\section{Zika virus}

A minimum $R R Z_{0 \rightarrow 1}$ resulting in a detectable outbreak was not identifiable for the scenarios of regular and enhanced surveillance. In both cases, the EORR and the EOCR were always less than one and decreased progressively with increasing $\mathrm{RRZ}_{0 \rightarrow 1}$ (Table 1; Additional file 1 , item 6). For instance, for enhanced surveillance the EORR and EOCR were 0.95 and 0.85 for $\mathrm{RRZ}_{0 \rightarrow 1}=2$ and 0.78 and 0.70 for $R R Z_{0 \rightarrow 1}=5$, respectively. As expected, the PFP decreased with higher $R R Z_{0 \rightarrow 1}$. However, under the scenario of enhanced surveillance the PFP reached $92.3 \%$ for $\mathrm{RRZ}_{0 \rightarrow 1}=2$ and $83.5 \%$ for $R R Z_{0 \rightarrow 1}=5$. Thus, for these scenarios, only 1 out of 13 and 1 out of 6 cases detected through enhanced surveillance were true ZIKV infection cases.

In the scenario of serologic based surveillance, an outbreak was detectable for $\mathrm{RRZ}_{0 \rightarrow 1} \geq 1.10$. In that case, the EORR was 1.01, but the EOCR was 0.91. Moreover, the EOCR was $>1$ only for $\mathrm{RRZ}_{0 \rightarrow 1} \geq 2.4$. Even for 
Table 1 Expected Observed Risk Ratios and Case Ratios and Proportion of False Positive Cases of Zika Virus Infection During an Outbreak, by Type of Surveillance, Increase in Infection Risk, and Case Definition Sensitivity and Specificity

\begin{tabular}{|c|c|c|c|c|c|c|}
\hline & $\mathrm{RRZ}_{0 \rightarrow 1}{ }^{\mathrm{a}}$ & $\begin{array}{l}\text { Case definition } \\
\text { sensitivity }\end{array}$ & $\begin{array}{l}\text { Case definition } \\
\text { specificity }\end{array}$ & $\begin{array}{l}\text { Expected observed } \\
\text { risk ratio }\end{array}$ & $\begin{array}{l}\text { Expected observed } \\
\text { case ratio }\end{array}$ & $\begin{array}{l}\text { False positive } \\
\text { proportion }\end{array}$ \\
\hline \multirow[t]{4}{*}{ Regular surveillance ${ }^{b}$} & 1 & 2.0 & 95.9 & 1.00 & 0.90 & 94.89 \\
\hline & 2 & 2.0 & 95.9 & 0.95 & 0.85 & 92.27 \\
\hline & 5 & 2.0 & 95.9 & 0.78 & 0.70 & 83.52 \\
\hline & 8 & 2.0 & 95.9 & 0.62 & 0.56 & 73.11 \\
\hline \multirow[t]{4}{*}{ Enhanced surveillance ${ }^{c}$} & 1 & 9.8 & 79.7 & 1.00 & 0.90 & 94.89 \\
\hline & 2 & 9.8 & 79.7 & 0.95 & 0.85 & 92.27 \\
\hline & 5 & 9.8 & 79.7 & 0.78 & 0.70 & 83.52 \\
\hline & 8 & 9.8 & 79.7 & 0.62 & 0.56 & 73.11 \\
\hline \multirow[t]{4}{*}{ Serologic surveillance ${ }^{d}$} & 1 & 37.7 & 81.1 & 1.00 & 0.90 & 81.86 \\
\hline & 2 & 37.7 & 81.1 & 1.09 & 0.98 & 74.36 \\
\hline & 5 & 37.7 & 81.1 & 1.36 & 1.23 & 55.17 \\
\hline & 8 & 37.7 & 81.1 & 1.63 & 1.47 & 39.77 \\
\hline
\end{tabular}

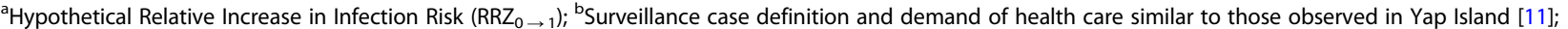
'Surveillance case definition similar to the one used in Yap Island with a five-fold increase in the demand of health care (detection probability); ${ }^{d}$ Surveillance based of serologic surveys of random samples of the population

larger values of the $R R Z_{0 \rightarrow 1}$ the EORR and the EOCR were strongly biased towards the null. For instance, for $\mathrm{RRZ}_{0 \rightarrow 1}=5$ the EORR and the EOCR were 1.36 and 1.23 , and the PFP was 55\%. Thus, even when the risk of ZIKV increased 5-fold during the outbreak, less than half of all cases of ZIKV infection detected through serologic surveillance were true positive cases.

\section{Microcephaly}

Outbreaks of all microcephaly were detectable for $\mathrm{HRI}_{Z \rightarrow M} \geq 2.00$, regardless of the level of sensitivity and specificity of the diagnosis, but the expected observed prevalence ratio (EOPR) was less than 1.10 in all cases (Table 2; Additional file 1, item 7). In contrast, outbreaks of severe microcephaly were detectable only for $\mathrm{HRI}_{\mathrm{Z} \rightarrow \mathrm{M}} \geq$ 24.00, but the EOPR was only 1.48. Even when the $\mathrm{HRI}_{\mathrm{Z} \rightarrow \mathrm{M}}$ was as high as 15 , the EOPR was $\leq 1.41$ for both all and severe microcephaly, regardless of sensitivity and specificity
(Tables 3 and 4; Additional file 1, item 8). When ZIKV infection did not increase microcephaly prevalence $\left(\mathrm{HRI}_{\mathrm{Z} \rightarrow \mathrm{M}}=\right.$ 1 ), the PFP for all microcephaly and severe microcephaly ranged from 22.6 to $56.6 \%$ and from 34.7 to $82.5 \%$, respectively, depending on the sensitivity and specificity of $\mathrm{HC}$ measurements (Tables 3 and 4).

\section{Guillain-Barré syndrome}

Under ideal conditions, when the sensitivity and specificity for detecting GBS cases were both $100 \%$, outbreaks of GBS were detected when $\mathrm{HRI}_{\mathrm{Z} \rightarrow \mathrm{G}} \geq 4.0$ (Table 5; Additional file 1, item 9). However, the minimum $\mathrm{HRI}_{Z \rightarrow G}$ resulting in a detectable outbreak increased for decreasing values of specificity. For the estimated sensitivity of $82.1 \%$, outbreaks were detected if $\mathrm{HRI}_{\mathrm{Z} \rightarrow \mathrm{G}} \geq 7, \mathrm{HRI}_{\mathrm{Z} \rightarrow \mathrm{G}} \geq 8$, and $\mathrm{HRI}_{Z \rightarrow G} \geq 9$ for specificities of $91.7,88.9$, and $80.6 \%$, respectively.

Table 2 Minimum Hypothetical and Expected Observed Prevalence Ratio to Detect an Outbreak of Microcephaly if Zika Virus Infection Risk Doubles, by Sensitivity and Specificity of Microcephaly Case Detection

\begin{tabular}{llllll}
\hline Microcephaly & $\begin{array}{l}\text { TEM }^{\text {a }} \\
(\mathrm{cm})\end{array}$ & $\begin{array}{l}\text { Sensitivity } \\
(\%)\end{array}$ & $\begin{array}{l}\text { Specificity } \\
(\%)\end{array}$ & \multicolumn{2}{l}{ Prevalence ratio } \\
\cline { 5 - 6 } & 0.24 & 85.1 & 99.4 & 2.00 & Hypothetical \\
\hline All & 0.42 & 77.6 & 98.8 & 2.00 & 1.06 \\
& 0.71 & 91.2 & 97.2 & 2.00 & 1.04 \\
Severe & 0.24 & 81.9 & 99.9 & 24.00 & 1.03 \\
& 0.42 & 75.0 & 99.9 & 27.50 & 1.48 \\
& 0.71 & 65.9 & 99.6 & 39.50 & 1.43 \\
\hline
\end{tabular}

a TEM: Technical error of head circumference measurements. TEM=0.71 came from Bhushan et al. (J Clin Epidemiol Vol. 44 (10):1027-1035, 1991), but values of sensitivity and specificity for all microcephaly were taken directly from their article, while those for severe were obtained by simulation. All other TEM values came from Onis (Acta Pædiatrica, 2006; Suppl 450:38-46) and were used to estimate sensitivity and specificity by simulation 
Table 3 Expected Observed Prevalence Ratio of All Microcephaly and Proportion of False Positive Cases During an Outbreak of Zika Virus Infection, by Increase in the Prevalence of Microcephaly in Newborn of Infected Mothers, and Sensitivity and Specificity of Microcephaly Case Detection

\begin{tabular}{|c|c|c|c|c|c|c|}
\hline$\overline{\mathrm{HRI}} \mathrm{Z \rightarrow M}$ in prevalence ratio ${ }^{\mathrm{a}}$ & $\begin{array}{l}\text { Intra-observer } \\
\text { TEM }^{\mathrm{b}}\end{array}$ & $\begin{array}{l}\text { Prevalence } \\
\text { ratio }^{c}\end{array}$ & Sensitivity (\%) & Specificity (\%) & $\begin{array}{l}\text { Expected observed } \\
\text { prevalence ratio }\end{array}$ & $\begin{array}{l}\text { Proportion of false } \\
\text { positives (\%) }\end{array}$ \\
\hline 1 & 0.24 & 1.00 & 85.1 & 99.4 & 1.00 & 22.6 \\
\hline 5 & 0.24 & 1.23 & 85.1 & 99.4 & 1.19 & 15.6 \\
\hline 10 & 0.24 & 1.38 & 85.1 & 99.4 & 1.33 & 11.1 \\
\hline 15 & 0.24 & 1.47 & 85.1 & 99.4 & 1.41 & 8.6 \\
\hline 1 & 0.71 & 1.00 & 91.8 & 97.2 & 1.00 & 56.6 \\
\hline 5 & 0.71 & 1.23 & 91.8 & 97.2 & 1.12 & 45.2 \\
\hline 10 & 0.71 & 1.38 & 91.8 & 97.2 & 1.22 & 35.9 \\
\hline 15 & 0.71 & 1.47 & 91.8 & 97.2 & 1.30 & 29.6 \\
\hline
\end{tabular}

${ }^{a} \mathrm{HRI}_{Z \rightarrow M}$ : Hypothetical relative increase in the prevalence of microcephaly

${ }^{b}$ TEM: Intraobserver technical error of measurement of head circumference

c Prevalence ratio of microcephaly (outbreak vs non-outbreak period) under perfect diagnostic sensitivity and specificity

When ZIKV infection was not associated with GBS risk $\left(\mathrm{HRI}_{\mathrm{Z} \rightarrow \mathrm{G}}=1\right)$, the PFP varied with specificity, from 34 to $59 \%$ and from 50 to $72 \%$, for low and high incidence of peripheral neuropathy, respectively (Table 6; Additional file 1, item 10). Regardless of $\mathrm{HRI}_{\mathrm{Z} \rightarrow \mathrm{G}}$ value, the misclassification-corrected EORR were small and decreased with decreasing specificity. Indeed, for specificity of $100 \%$ and $\mathrm{HRI}_{\mathrm{Z} \rightarrow \mathrm{G}}=10$, the EORR was only 1.47 . For the lowest specificity the minimum PFP was $33.8 \%$ or higher in all scenarios. For higher values of specificity, the PFP was below $30 \%$, regardless of the HRR, but only if the incidence of peripheral neuropathy was low. When the incidence of peripheral neuropathy was high, the PFP ranged from 24.5 to $61.0 \%$, if $\mathrm{HRI}_{\mathrm{Z} \rightarrow \mathrm{G}}>1$.

\section{Discussion}

Our findings suggest surveillance systems for ZIKV, microcephaly, and GBS in Latin America have a limited capacity to detect outbreaks. ZIKV outbreaks were detectable only through serological surveillance. Outbreaks of all and severe microcephaly were detected only when ZIKV infection increased the frequency of these conditions at least two and 24 times, respectively. Outbreaks of GBS were detectable only when GBS risk was at least eight times higher among ZIKV infected individuals. Finally, under most scenarios, cases of ZIKV infection, microcephaly, and GBS were more likely false positive than true positive cases.

While judging these findings, one should carefully consider the validity of study assumptions.

\section{ZIKV infection}

We assumed a background risk of ZIKV infection of $10 \%$ and a doubling of the risk during an outbreak. A $10 \%$ risk corresponds to about half the risk in Brazil [41] and Puerto Rico [42]. A doubling of the risk is also consistent with a lowest limit of $10 \%$, a most likely value of $25 \%$, and an interquartile range of 19 to $33 \%$ suggested

Table 4 Expected Observed Prevalence Ratio of Severe Microcephaly and Proportion of False Positive Cases During an Outbreak of Zika Virus Infection, by Increase in the Prevalence of Microcephaly in Newborn of Infected Mothers, and Sensitivity and Specificity of Microcephaly Case Detection

\begin{tabular}{|c|c|c|c|c|c|c|}
\hline $\mathrm{HRI}_{Z \rightarrow M}$ in prevalence ratio ${ }^{a}$ & $\begin{array}{l}\text { Intra-observer } \\
\text { TEM }^{\text {b }}\end{array}$ & $\begin{array}{l}\text { Prevalence } \\
\text { ratio }^{c}\end{array}$ & Sensitivity (\%) & Specificity (\%) & $\begin{array}{l}\text { Expected observed } \\
\text { prevalence ratio }\end{array}$ & $\begin{array}{l}\text { Proportion of false } \\
\text { positives (\%) }\end{array}$ \\
\hline 1 & 0.24 & 1.00 & 81.9 & 99.9 & 1.00 & 34.7 \\
\hline 5 & 0.24 & 1.21 & 81.9 & 99.9 & 1.14 & 24.7 \\
\hline 10 & 0.24 & 1.35 & 81.9 & 99.9 & 1.26 & 18.4 \\
\hline 15 & 0.24 & 1.50 & 81.9 & 99.9 & 1.41 & 14.7 \\
\hline 1 & 0.71 & 1.00 & 65.9 & 99.6 & 1.00 & 82.5 \\
\hline 5 & 0.71 & 1.21 & 65.9 & 99.6 & 1.06 & 74.5 \\
\hline 10 & 0.71 & 1.35 & 65.9 & 99.6 & 1.10 & 66.8 \\
\hline 15 & 0.71 & 1.50 & 65.9 & 99.6 & 1.16 & 60.5 \\
\hline
\end{tabular}

${ }^{\mathrm{a}} \mathrm{HRI}_{\mathrm{Z} \rightarrow \mathrm{M}}$ : Hypothetical relative increase in the prevalence of microcephaly

b TEM: Intraobserver technical error of measurement of head circumference

c Prevalence ratio of microcephaly (outbreak vs non-outbreak period) under perfect diagnostic sensitivity and specificity 
Table 5 Minimum Hypothetical Relative Increase in Risk $\left(\mathrm{HRI}_{Z} \rightarrow\right.$ G) to Detect an Outbreak of Guillain-Barré Syndrome and Expected Observed Risk Ratios if the Risk if Zika Virus Infection Doubles During an Outbreak ${ }^{\mathrm{a}}$

\begin{tabular}{lll}
\hline Sensitivity/specificity (\%) & $\mathrm{HRI}_{Z \rightarrow G}$ in $^{\mathrm{GBS}}$ risk $^{\mathrm{c}}$ & Observed risk ratio \\
\hline $100 / 100$ & 4 & 1.18 \\
$82.1 / 100$ & 5 & 1.23 \\
$82.1 / 91.7$ & 7 & 1.30 \\
$82.1 / 88.9$ & 8 & 1.33 \\
$82.1 / 80.6$ & 9 & 1.36
\end{tabular}

${ }^{a}$ Corrected for non-differential misclassification due to a sensitivity of $82.1 \%$ and varying levels of specificity of the GBS case definition

${ }^{\mathrm{b}}$ A fixed level of sensitivity was obtained by averaging findings from studies assessing the validity of Brighton criteria in adults

${ }^{\mathrm{C}} \mathrm{HRI}_{\mathrm{Z} \rightarrow \mathrm{G}}$ : Minimum Hypothetical Relative Increase in Risk of

Guillain-Barré síndrome by Ellington et al. in a review of existing data [43]. Higher levels of baseline ZIKV infection risk would lower the chances of detecting an outbreak, due to a smaller pool of susceptible individuals $[6,44]$.

Values of sensitivity and specificity of ZIKV infection surveillance case definition were derived from the Yap Island study [11]. However, they are valid in Latin America, regardless of differences in prevalence, because sensitivity applies only to cases and specificity applies only to non-cases of a disease. The specificity of case definition for regular surveillance was high (95\%), because it was applied to a self-selected sample of individuals who got medical care. This "pre-screening" improves specificity by increasing the prevalence of ZIKV infection among health care seekers. In contrast, the sensitivity was too low (2\%). This is not surprising, because the definition only catches the $37.7 \%$ of all cases that are symptomatic [11] and only $11.5 \%$ of

Table 6 True and Expected Observed Risk Ratio of Guillain-Barré Syndrome (GBS) During an Outbreak of Zika Virus (ZIKV) Infection, by Hypothetical Increase in GBS Risk Among ZIKV Infected Individuals and by Specificity and Sensitivity of the GBS Case Definition Used for Surveillance

\begin{tabular}{|c|c|c|c|c|c|c|}
\hline Hypothetical risk ratio & Specificity (\%) & $\begin{array}{l}\text { Incidence peripheral } \\
\text { neuropathy }\end{array}$ & $\begin{array}{l}\text { True GBS } \\
\text { risk ratio }^{\text {a }}\end{array}$ & $\begin{array}{l}\text { Expected observed } \\
\text { risk ratio } b\end{array}$ & $\operatorname{PFP}^{\mathrm{C}}(\%)$ & $\begin{array}{l}\text { Number of false } \\
\text { positive GBS cases }\end{array}$ \\
\hline 1 & 100.0 & $3.3 / 10,000$ & 1.00 & 1.00 & 0.0 & 0 \\
\hline 1 & 91.7 & & & & 54.5 & 454 \\
\hline 1 & 88.9 & & & & 62.4 & 631 \\
\hline 1 & 80.6 & & & & 75.2 & 1153 \\
\hline 5 & 100.0 & $3.3 / 10,000$ & 1.29 & 1.29 & 0.0 & 0 \\
\hline 5 & 91.7 & & & 1.18 & 40.7 & 414 \\
\hline 5 & 88.9 & & & 1.16 & 49.4 & 591 \\
\hline 5 & 80.6 & & & 1.12 & 64.8 & 1113 \\
\hline 10 & 100.0 & $3.3 / 10,000$ & 1.47 & 1.47 & 0.0 & 0 \\
\hline 10 & 91.7 & & & 1.33 & 29.2 & 364 \\
\hline 10 & 88.9 & & & 1.30 & 37.9 & 540 \\
\hline 10 & 80.6 & & & 1.23 & 54.6 & 1063 \\
\hline 1 & 100.0 & $5.6 / 10,000$ & 1.00 & 1.00 & 0.0 & 0 \\
\hline 1 & 91.7 & & & & 68.4 & 822 \\
\hline 1 & 88.9 & & & & 74.7 & 1122 \\
\hline 1 & 80.6 & & & & 84.1 & 2012 \\
\hline 5 & 100.0 & $5.6 / 10,000$ & 1.29 & 1.29 & 0.0 & 0 \\
\hline 5 & 91.7 & & & 1.14 & 56.4 & 782 \\
\hline 5 & 88.9 & & & 1.12 & 64.2 & 1082 \\
\hline 5 & 80.6 & & & 1.08 & 76.5 & 1971 \\
\hline 10 & 100.0 & $5.6 / 10,000$ & 1.47 & 1.47 & 0.0 & 0 \\
\hline 10 & 91.7 & & & 1.27 & 45.3 & 731 \\
\hline 10 & 88.9 & & & 1.24 & 53.8 & 1032 \\
\hline 10 & 80.6 & & & 1.17 & 68.5 & 1921 \\
\hline
\end{tabular}

${ }^{a}$ Risk ratio of GBS during the ZIKV outbreak, assuming sensitivity of $82.1 \%$ and specificity of $100 \%$ for the diagnosis of GBS; ${ }^{b}$ Risk ratio of GBS during the ZIKV outbreak, after accounting for misclassification of GBS; ' ${ }^{\circ}$ Proportion of false positive cases of GBS 
symptomatic cases seek medical care $[45,46]$. Thus, the upper limit of sensitivity is $4.3 \%$.

Due to the poor accuracy of ZIKV infection case definition, regular surveillance could show a decrease in incidence, even if the incidence has increased several fold. This could explain why incidence estimates from surveillance data has been orders of magnitude lower than those from serologic studies [11, 45], simulation studies [41, 47], and previous experience with viruses transmitted by the same vectors [43]. Also, this suggests regular ZIKV infection surveillance may be of little public health benefit.

Serologic surveillance seems the best option for ZIKV infection surveillance in Latin America. If serologic tests used in the Yap Island study were used, outbreaks would be detectable, though most cases would still be false positive. Yearly serologic surveys offer important advantages, compared to regular surveillance. They reduce the PFP; reflect trends in the whole population, instead of just health care seekers; provide needed data on background herd immunity [44]; and generate diagnostic accuracy data useful to correct risk estimates from regular surveillance [7]. Surveys could be conducted in random samples of a few hundred individuals (Additional file 1, item 12). Whether or not surveys are more cost-effective than regular surveillance is a moot point, since outbreaks cannot be detected using the latter. Well-planned serologic testing in random or haphazard samples of patients attending sentinel clinics could have similar benefits.

Unfortunately, better tests are needed for accurate diagnosis of ZIKV infection [48]. Moreover, the PFP cases would increase and outbreaks will be harder to detect if the Centers for Diseases Control's (CDC) new guidelines to interpret serologic tests are used, as they improve sensitivity, in detriment of specificity [49].

In view of the uncertainty regarding the etiological role of ZIKV infection [5, 50-52], and the high PFP cases of ZIKV infection, even with serological testing, we should carefully ponder whether providing possibly infected patients with advice on conception attempts, changes in sexual behavior, and pregnancy outcomes is beneficial, cost-effective, or even ethical [53].

\section{Microcephaly}

Due to the lack of published data, we estimated the accuracy of the diagnosis of microcephaly in normal weight newborn by simulation. Large studies of child growth standards $[16,54]$, support our assumption of a normal distribution of $\mathrm{HC}$ values, and TEM values used for simulation came from previous studies $[18,20]$.

Current surveillance systems target "congenital syndrome associated with Zika virus infection", instead of all and severe microcephaly $[1,8,9]$. We focused on microcephaly because this is the main component of the postulated syndrome and it was possible to assess the accuracy if its diagnosis. Moreover, most components of the proposed syndrome are common findings in newborns with microcephaly of genetic and infectious origins [55, 56], and there is no evidence they cluster more frequently than expected in newborn from ZIKV-infected mothers [57]. More important, attributing all cases of microcephaly to ZIKV makes little sense. Indeed, about $50 \%$ of severe cases have a genetic etiology $[14,58]$, and 44 to $59 \%$ of non-severe cases could be due to low birth weight (Additional file 1, item 12). Moreover, some 10 to $33 \%$ of all cases should have maternal ZIKV infection, based on the risk of ZIKV infection [41-43], even if there is no association between the two conditions.

In spite of striking differences in prevalence, etiology, prognosis, and management [55, 59], current surveillance systems do not differentiate between severe and non-severe microcephaly $[1,8,60,61]$. Therefore, surveillance data are of limited value for characterizing disease burden, making decisions about case management, and developing and allocating health resources.

Outbreaks of all microcephaly during a ZIKV infection outbreak will be detectable through regular surveillance if the risk of microcephaly is at least twice higher among infected mothers, but outbreaks of severe microcephaly would be virtually undetectable. Moreover, the PFP for microcephaly will be high, even if maternal ZIKV infection increased microcephaly prevalence by at least 15 times. Such a high prevalence ratio is very unlikely, since evidence from observational and ecological studies in Brazil and Colombia does not support an increased risk of microcephaly in newborn of ZIKV-infected mothers [5, 57].

It is uncertain whether adding non-severe microcephaly to the traditional surveillance of preterm birth and low-birth-weight [14] is justified in terms of its incremental cost-effectiveness to prevent perinatal and infant mortality. Indeed, half the cases of non-severe microcephaly may be due to low-birth-weight, and postnatal nutritional interventions is the cornerstone for the management of both conditions [62-65]. On the other hand, it is unlikely low-income countries will keep severe microcephaly as a public health priority, in view of the high impact of competing causes of perinatal and infant mortality, such as low birth weight, preterm birth, and neonatal asphyxia. Therefore, strengthening existing perinatal surveillance hospital networks may be the best option for surveillance of severe microcephaly $[66,67]$.

\section{Guillain-Barré syndrome}

We used a GBS incidence of 2/100,000 in our analysis, which is higher than that in seven Latin American countries (1.41/100,000; Additional file 1, item 13) [3]. In addition, we evaluated scenarios where the risk of GBS 
among ZIKV-infected individuals increased five and 10 times. Such large increases in risk are unrealistic, since evidence from published studies $[47,68]$ do not support a causal ZIKV-GBS link [5, 50]. In addition, we used all published data to estimate the accuracy of a GBS diagnosis and the incidence of non-diabetic non-GBS peripheral neuropathy. Although these estimates may not strictly apply to Latin America, we believe they are robust enough for an informative assessment of GBS surveillance.

GBS surveillance data could be useful for health planning and program evaluation, but are of little use for outbreak control. In Latin America, GBS surveillance is compounded by the limited or non-existing capacity to perform motor nerve conduction tests, and to draw and analyze cerebrospinal fluid samples for cell count and protein concentration in most clinics. Without these tests, most GBS cases would have Brighton certainty levels $\leq 3$, and a definite diagnosis may not be made until verifying the polyneuropathy was transient, something that could take several weeks $[22,69]$. This compromises timely/accurate reporting of GBS cases. Thus, GBS surveillance may add little value to the analysis of data from existing sources $[1,2]$.

Assuming ongoing GBS surveillance is devoid of potential harm may be risky. As shown in this assessment, surveillance could result in large numbers of false positive cases. Premature declarations of GBS as a complication of ZIKV infection [1, 2], may contribute to misdiagnosing GBS-mimics as GBS cases. This could alter the distribution of scarce health resources in the region, distort health priorities and planning, increase the cost of surveillance activities, and add unnecessary testing, treatment, and morbidity in false positive GBS cases [22].

\section{Conclusions}

Our findings suggest it is unlikely that outbreaks of ZIKV infection and putative related outcomes in Latin America will be detected through surveillance systems based on current guidelines $[1,2]$. In consequence, it is unlikely these systems would be useful in detecting and curtailing impending or ongoing outbreaks, quantifying burden of disease, identifying factors driving risk, assessing the effectiveness of control measures, or improving clinical care.

In spite of uncertainty in some assumptions and parameters, we believe our findings are sufficiently robust to inform public health policies that, so far, seem mostly supported by questionable causal links and hopes of potential benefits. Policies in response to the ZIKV outbreaks were timely implemented, in a context of limited knowledge about causal links. Unfortunately, knowledge and data about non-causal issues, such as disease burden, diagnostic accuracy, and cost-effectiveness of potential interventions were given little weight when formulating surveillance guidelines. Though they are undoubtedly intended to improve and save lives, ZIKV public health policies should be based on previous experience and scientific knowledge, lest they become irrelevant and harmful for those they meant to protect [70].

\section{Additional file}

Additional file 1: Appendix-Zika Surveillance-BMC PublicHealth. (PDF $844 \mathrm{~kb})$

\section{Abbreviations}

CDC: Centers for Diseases Control; ELISA: Enzyme-Linked Immunosorbent Assay; EOCR: Expected observed case ratio; EORR: Expected observed risk ratio; GBS: Guillain-Barré syndrome; $\mathrm{HC}$ : Head circumference; $\mathrm{HRI}_{Z \rightarrow}$ $G$ : Hypothetical relative increase in risk of GBS in Zika virus infected individuals; $\mathrm{HRI}_{Z} \rightarrow \mathrm{M}$ : Hypothetical relative increase in risk of microcephaly among Zika virus infected individuals; IgM: Immunoglobulin M; $\mathrm{NZ}_{(-)}$: Number of ZIKV non-infected individuals during the outbreak; $\mathrm{NZ}_{(+)}$: Numbers of ZIKV infected individuals during the outbreak; PFP: Proportion of false positive cases; $R_{0}$ : Baseline risk of Guillain-Barré syndrome; $R R Z_{0 \rightarrow 1}$ : Hypothetical relative increase in the risk of Zika virus infection during the outbreak period; RT-PCR: Reverse transcription polymerase chain reaction; $R Z_{0}$ : Risk of Zika virus infection during the nonoutbreak period; $R Z_{1}$ : Risk of Zika virus infection during the outbreak period; SD: Standard deviation; TEM: Technical error of measurements; ZIKV: Zika virus

\section{Availability of data and materials}

All data used in this study are publicly available. They are referenced in the manuscript, as well as in the Appendix. The Appendix also includes computer code and data needed to replicate all the analyses.

\section{Authors' contributions}

Dr. Bautista conceived the idea for the study and wrote the draft of the manuscript. He wrote most of the code and conducted most of the data analysis. Dr. Herrera conducted some of the analyses and independently checked all the code. Both authors were involved in identifying and reviewing studies and data relevant for the assessment and both read and approved the final manuscript.

\section{Authors' information}

$\mathrm{LB}$ is a physician epidemiologist, with a DrPH in Epidemiology from Johns Hopkins University (infectious diseases). He is currently an Associate Professor at the University of Wisconsin, Madison, and his main research resides on the impact of cardiovascular diseases in Latin America. VMH is a physician epidemiologist, with a PhD in Epidemiology from the University of Wisconsin, currently Associate Professor at the Universidad Autónoma de Bucaramanga, Colombia. His research is mostly focused on dengue and Zika virus infections.

Ethics approval and consent to participate Not applicable.

\section{Competing interests}

The authors declare that they have no competing interests.

\section{Publisher's Note}

Springer Nature remains neutral with regard to jurisdictional claims in published maps and institutional affiliations.

\section{Author details}

'Department of Population Health Sciences, School of Medicine and Public Health, University of Wisconsin at Madison, 610 Walnut Street, WARF 703, Madison, WI 53726-2397, USA. ${ }^{2}$ Center for Biomedical Research, Universidad Autónoma de Bucaramanga, Bucaramanga, Colombia. 


\section{Received: 4 December 2017 Accepted: 14 May 2018}

\section{Published online: 24 May 2018}

\section{References}

1. Pan American Health O. Guidelines for Zika virus disease and complications surveillance. Washington, D.C.: PAHO; 2016.

2. World Health O: Surveillance for Zika virus infection, microcephaly and Guillain-Barré syndrome: interim guidance. http://www.who.int/ emergencies/zika-virus/situation-report/14-april-2016/en/. 2016.

3. dos Santos T, Rodriguez A, Almiron M, Sanhueza A, Ramon P, de Oliveira WK, Coelho GE, Badaró R, Cortez J, Ospina M, et al. Zika virus and the Guillain-Barré syndrome -case series from seven countries. N Engl J Med. 2016;375:1598-601.

4. Cuevas EL, Tong VT, Rozo N, Valencia D, Pacheco O, Gilboa SM, Mercado M, Renquist CM, González M, Ailes EC. Preliminary report of microcephaly potentially associated with Zika virus infection during pregnancy-Colombia, January-November 2016. MMWRMorbidity and mortality weekly report. 2016;65(49):1409.

5. Bautista LE: On the temporal association of outbreaks of Zika virus infection, newborn microcephaly, and Guillain-Barré syndrome. J Public Health Emerg; July 20172017.

6. Okuno Y, Fukunaga T, Tadano M, Fukai K, Ikeda T, Sekii K, Ariyoshi H. Serological studies on volunteers inoculated experimentally with a dengue virus strain in 1943. Biken J. 1983:26(4):161-3.

7. Lash TL, Fox MP, Fink AK. Misclassification. In: Applying quantitative bias analysis to epidemiologic data. Dordrecht: Springer; 2009. p. 79-108.

8. Martnez MLO, Duran MEM, García OEP, Quijada H, Ortiz ELC, Cuevas EL. Protocolo de Vigilancia en Salud Pública. Vigilancia intensificada en salud pública de la microcefalia y otros defectos congénitos del Sistema Nervioso Central por virus Zika.

9. Tolosa N: Protocolo de Vigilancia en Salud Pública. Enfermedad por virus Zika, 2016 [citado 21 Feb 2016]. In.

10. Badurdeen S, Valladares DB, Farrar J, Gozzer E, Kroeger A, Kuswara N Ranzinger SR, Tinh HT, Leite P, Mahendradhata Y, et al. Sharing experiences: towards an evidence based model of dengue surveillance and outbreak response in Latin America and Asia. BMC Public Health. 2013;13(1):607.

11. Duffy MR, Chen TH, Hancock WT, Powers AM, Kool JL, Lanciotti RS, Pretrick M, Marfel M, Holzbauer S, Dubray C, et al. Zika virus outbreak on Yap Island, Federated States of Micronesia. N Engl J Med. 2009;360(24):2536-43.

12. Pepe MS. The statistical evaluation of medical tests for classification and prediction. Oxford: Oxford University Press; 2004.

13. Broemeling LD. Bayesian biostatistics and diagnostic medicine: CRC press; 2007.

14. Ashwal S, Michelson D, Plawner L, Dobyns WB. Practice parameter: evaluation of the child with microcephaly (an evidence-based review) report of the quality standards Subcommittee of the American Academy of neurology and the practice Committee of the Child Neurology Society. Neurology. 2009;73(11):887-97.

15. Leviton A, Holmes LB, Allred EN, Vargas J. Methodologic issues in epidemiologic studies of congenital microcephaly. Early Hum Dev. 2002 69(2002):91-105.

16. Villar J, Ismail LC, Victora CG, Ohuma EO, Bertino E, Altman DG, Lambert A, Papageorghiou AT, Carvalho M, Jaffer YA, et al. International standards for newborn weight, length, and head circumference by gestational age and sex: the newborn cross-sectional study of the INTERGROWTH-21 st project. Lancet. 2014;384(9946):857-68.

17. Chumlea WC, Guo S, Kuczmarski RJ, Johnson CL, Leahy CK. Reliability for anthropometric measurements in the Hispanic health and nutrition examination survey (HHANES 1982-1984). Am J Clin Nutr. 1990:51(5):902S-7S

18. de Onis M: Reliability of anthropometric measurements in the WHO multicentre growth reference study. Acta PaediatricaSupplement 2006, 95(s450):38-46.

19. Brenner HERM, Gefeller OLAF. Variation of sensitivity, specificity, likelihood ratios and predictive values with disease prevalence. Stat Med. 1997;16(9): 981-91.

20. Bhushan $\mathrm{V}$, Paneth $\mathrm{N}$. The reliability of neonatal head circumference measurement. J Clin Epidemiol. 1991;44(10):1027-35.

21. Hughes RAC, Rees JH. Clinical and epidemiologic features of Guillain-Barré syndrome. J Infect Dis. 1997;176(Supplement_2):S92-8.

22. Levin KH. Variants and mimics of Guillain Barré syndrome. Neurologist. 2004; 10(2):61-74
23. Fokke C, van den Berg B, Drenthen J, Walgaard C, van Doorn PA, Jacobs BC. Diagnosis of Guillain-Barré syndrome and validation of Brighton criteria. Brain. 2014;137:33-43.

24. Choe YJ, Cho H, Bae GR, Lee JK. Guillain-Barré syndrome following receipt of influenza a (H1N1) 2009 monovalent vaccine in Korea with an emphasis on Brighton collaboration case definition. Vaccine. 2011;29(11):2066-70.

25. Dieleman J, Romio S, Johansen K, Weibel D, Bonhoeffer J, Sturkenboom M. Guillain-Barré syndrome and adjuvanted pandemic influenza a (H1N1) 2009 vaccine: multinational case-control study in Europe. Br Med J. 2011;343

26. Islam MB, Islam Z, Farzana KS, Sarker SK, Endtz HP, Mohammad QD, Jacobs BC. Guillain-Barré syndrome in Bangladesh: validation of Brighton criteria. J Peripher Nerv Syst. 2016;21(4):345-51.

27. Military Vaccine A. Predictive value of surveillance case definitions of Guillain-Barre syndrome in vaccine safety assessment. Medical Surveillance Monthly Report. 2012;19(5):8-9.

28. Esposito S, Longo MR. Guillain-Barre syndrome. AutoimmunRev. 2016;

29. Hughes RAC, Cornblath DR. Guillain-Barré syndrome. Lancet. 2005; 366(9497):1653-66.

30. Katusic SK, Beard CM, Wiederholt WC, Bergstralh EJ, Kurland LT. Incidence, clinical features, and prognosis in Bell's palsy, Rochester, Minnesota, 19681982. Ann Neurol. 1986;20(5):622-7.

31. Yanagihara N. Incidence of Bell's palsy. Ann Otol Rhinol Laryngol Suppl. 1988;137:3-4.

32. Brandenburg NA, Annegers JF. Incidence and risk factors for Bell's palsy in Laredo, Texas: 1974-1982. Neuroepidemiology. 1993;12(6):313-25.

33. Radhakrishnan K, Litchy WJ, O'Fallon WM, Kurland LT. Epidemiology of cervical radiculopathy. A population-based study from Rochester, Minnesota, 1976 through 1990. Brain. 1994;117(Pt 2):325-35.

34. Vessey MP, Villard-Mackintosh L, Yeates D. Epidemiology of carpal tunnel syndrome in women of childbearing age. Findings in a large cohort study. Int J Epidemiol. 1990;19(3):655-9.

35. de Krom MC, Knipschild PG, Kester AD, Thijs CT, Boekkooi PF, Spaans F. Carpal tunnel syndrome: prevalence in the general population. J Clin Epidemiol. 1992:45(4):373-6.

36. Stevens JC, Sun S, Beard CM, O'Fallon WM, Kurland LT. Carpal tunnel syndrome in Rochester, Minnesota, 1961 to 1980. Neurology. 1988;38(1):134-8.

37. Murakami S, Mizobuchi M, Nakashiro Y, Doi T, Hato N, Yanagihara N. Bell palsy and herpes simplex virus: identification of viral DNA in endoneurial fluid and muscle. Ann Intern Med. 1996;124(1 Pt 1):27-30.

38. Beghi E, Kurland LT, Mulder DW, Nicolosi A. Brachial plexus neuropathy in the population of Rochester, Minnesota, 1970-1981. Ann Neurol. 1985;18(3):320-3.

39. Baldereschi M, Inzitari M, Di Carlo A, Farchi G, Scafato E, Inzitari D, Group IW. Epidemiology of distal symmetrical neuropathies in the Italian elderly. Neurology. 2007;68(18):1460-7.

40. Rudolph T, Farbu E. Hospital-referred polyneuropathies-causes, prevalences, clinical- and neurophysiological findings. Eur J Neurol. 2007;14(6):603-8.

41. Perkins AT, Siraj AS, Ruktanonchai CW, Kraemer MUG, Tatem AJ. Modelbased projections of Zika virus infections in childbearing women in the Americas. Nat Microbiol. 2016:1:16126.

42. Branswell H. Zika virus spreading rapidly across Puerto Rico. Stat.

43. Ellington SR, Devine O, Bertolli J. Estimating the number of pregnant women infected with zika virus and expected infants with microcephaly following the zika virus outbreak in Puerto Rico, 2016. JAMA Pediatr. 2016; 170(10):940-5.

44. Ferguson NM, Cucunubá ZM, Dorigatti I, Nedjati-Gilani GL, Donnelly CA Basáñez MG, Nouvellet P, Lessler J. Countering Zika in Latin America. Science. 2016:353(6297):353-4.

45. Aubry M, Teissier A, Huart M, Merceron S, Vanhomwegen J, Roche C, Vial AL, Teururai S, Sicard S, Paulous S, et al. Zika virus Seroprevalence, French Polynesia, 2014-2015. Emerg Infect Dis. 2017;23(4):669-72.

46. Kucharski AJ, Funk S, Eggo RM, Mallet HP, Edmunds WJ, Nilles EJ. Transmission dynamics of Zika virus in island populations: a modelling analysis of the 2013â_14 French Polynesia outbreak. PLoS Negl Trop Dis. 2016;10(5):e0004726.

47. Paploski IA, Prates AP, Cardoso CW, Kikuti M, Silva MM, Waller LA, Reis MG, Kitron U, Ribeiro GS. Time lags between exanthematous illness attributed to Zika virus, Guillain-Barre syndrome, and microcephaly, Salvador, Brazil. Emerg Infect Dis. 2016;22(8):1438-44.

48. David S, Angela S, Derek RS, Emelissa M, Nicole B, Charlene R, Leanne S, Kimberly H, Alyssia R, Maya T, et al. Evaluation of 5 commercially available Zika virus immunoassays. Emerg Infect Dis. 2017;23(9):1577. 
49. Oduyebo T, Polen KD, Walke HT. Update: interim guidance for health care providers caring for pregnant women with possible Zika virus exposure United States (including U.S. territories), July 2017. Morb Mortal Wkly Rep. 2017:66:781-93.

50. Bautista LE, Sethi AK. Association between Guillain-Barre syndrome and Zika virus infection. Lancet. 2016;387(10038):2599-600.

51. Leis AA, Stokic DS. Zika virus and Guillain-Barré syndrome: is there sufficient evidence for causality? Front Neurol. 2016;7:170.

52. Wiwanitkit V. Guillain-Barre syndrome and Zika virus infection. Arq Neuropsiquiatr. 2016;74(8):692.

53. Vouga M, Musso D, Schaub B, Panchaud A, Baud D. Zika virus: are we going too far? Lancet. 2017;389(10065):151.

54. WHO child growth standards: length/height for age, weight-for-age, weight-for-length, weight-for-height and body mass index-for-age, methods and development. Geneva: World Health Organization; 2006.

55. Abuelo D. Microcephaly syndromes. Semin Pediatr Neurol. 2007;14(3): $118-27$

56. Nickerson JP, Richner B, Santy K, Lequin MH, Poretti A, Filippi CG, Huisman TAGM. Neuroimaging of pediatric intracranial infection-part 2: TORCH, viral, fungal, and parasitic infections. J Neuroimaging. 2012;22(2):e52-63.

57. Bautista LE. Maternal Zika virus infection and newborn microcephaly —an analysis of the epidemiological evidence. Ann Epidemiol. 2017; In press

58. Cragan JD, Isenburg JL, Parker SE, Alverson CJ, Meyer RE, Stallings EB, Kirby RS, Lupo PJ, Liu JS, Seagroves A, et al. Population-based microcephaly surveillance in the United States, 2009 to 2013: an analysis of potential sources of variation. Birth Defects Research Part A: Clinical and Molecular Teratology. 2016;106(11):972-82.

59. Mighell AS, Johnstone ED, Levene M. Post-natal investigations: management and prognosis for fetuses with CNS anomalies identified in utero excluding neurosurgical problems. Prenat Diagn. 2009;29(4):442-9.

60. Ministerio de Salud P. Guía para la atención de embarazadas y recién nacidos afectados por el virus del Zika. República Dominicana: Santo Domingo; 2016.

61. Ministerio de Salud Pública y Asistencia S. Guía para la vigilancia y manejo de la infección del virus Zika y sus complicaciones en Guatemala. Guatemala: Ciudad Guatemala; 2016.

62. Imdad A, Bhutta ZA. Nutritional Management of the low Birth Weight/ preterm infant in community settings: a perspective from the developing world. J Pediatr. 2013;162(3):S107-14.

63. Lorenz JM, Whitaker AH, Feldman JF, Yudkin PL, Shen S, Blond A, PintoMartin JA, Paneth N. Indices of body and brain size at birth and at the age of 2 years: relations to cognitive outcome at the age of 16 years in low birth weight infants. J Dev Behav Pediatr. 2009;30(6):535-43.

64. Gale CR, Oâ_Tcallaghan FJ, Godfrey KM, Law CM, Martyn CN. Critical periods of brain growth and cognitive function in children. Brain. 2004;127(2):321-9.

65. Gale CR, O'Callaghan FJ, Bredow M, Martyn CN, Avon longitudinal study of $P$, children study T. The influence of head growth in fetal life, infancy, and childhood on intelligence at the ages of 4 and 8 years. Pediatrics. 2006; 118(4):1486-92.

66. Castilla EE Orioli IM. ECLAMC: the Latin-American collaborative study of congenital malformations. Public Health Genomics. 2004;7(2-3):76-94.

67. Mattos SS, Hazin SMV, Regis CT, JSSd A, Albuquerque FCL, Moser LRDN, Hatem TP, CPGd F, Mourato FA, Tavares TR, et al. A telemedicine network for remote paediatric cardiology services in north-East Brazil. Bull World Health Organ. 2015;93(12):881-7.

68. Cao-Lormeau VM, Blake A, Mons S, Lastère S, Roche C, Vanhomwegen J, Dub T, Baudouin L, Teissier A, Larre P, et al. Guillain-Barré syndrome outbreak associated with Zika virus infection in French Polynesia: a casecontrol study. Lancet. 2016;387(10027):1531-9.

69. Asbury AK, Arnason BG, Karp HR, McFarlin DE. Criteria for diagnosis of Guillain-Barre syndrome. Ann Neurol. 1978:3(6):565-6.

70. Malhotra VM. Freedom of expression and health: is the association causal? Lancet. 2016;388(10044):561.

\section{Ready to submit your research? Choose BMC and benefit from:}

- fast, convenient online submission

- thorough peer review by experienced researchers in your field

- rapid publication on acceptance

- support for research data, including large and complex data types

- gold Open Access which fosters wider collaboration and increased citations

- maximum visibility for your research: over $100 \mathrm{M}$ website views per year

At BMC, research is always in progress.

Learn more biomedcentral.com/submissions 